\title{
Changes in Collagen Orientation and Distribution in Keratoconus Corneas
}

\author{
Keith M. Meek, ${ }^{1}$ Stephen J. Tuft, ${ }^{2}$ Yifei Huang, ${ }^{3}$ Paulvinder S. Gill, ${ }^{1}$ Sally Hayes, ${ }^{1}$ \\ Richard H. Newton, ${ }^{1}$ and Antbony J. Bron ${ }^{4}$
}

Purpose. To map the collagen orientation and relative distribution of collagen fibrillar mass in keratoconus corneal buttons.

Methods. Structural analysis was performed by obtaining synchrotron $x$-ray scattering patterns across the samples at $0.25-\mathrm{mm}$ intervals. The patterns were analyzed to produce two-dimensional maps of the orientation of the lamellae and of the distribution of total and preferentially aligned lamellae.

Results. Compared with normal corneas, in keratoconus the gross organization of the stromal lamellae was dramatically changed, and the collagen fibrillar mass was unevenly distributed, particularly around the presumed apex of the cone.

Conclusions. The development of keratoconus involves a high degree of inter- and probably intralamellar displacement and slippage that leads to thinning of the central cornea and associated changes in corneal curvature. This slippage may be promoted by a loss of cohesive forces and mechanical failure in regions where lamellae bifurcate. (Invest Ophthalmol Vis Sci. 2005;46:1948-1956) DOI:10.1167/iovs.04-1253

$\mathrm{T}$ he quality of image formation on the retina depends on the shape and transparency of the optical media, including the cornea, the main refractive component of the eye. Corneal shape and transparency are maintained by the ordered arrangement of its collagen fibrils, which lie parallel to each other and to the plane of the cornea. ${ }^{1}$ In many animal corneas, these lamellae are not uniformly disposed ${ }^{2}$; and, in the human cornea, there is a preferred orientation in the inferior-superior and nasal-temporal directions, ${ }^{3,4}$ mainly in the posterior stroma. ${ }^{3}$ This preferred orientation occurs at the center of the cornea and is maintained to within $2 \mathrm{~mm}$ of the limbus, where a gradual change to a circular or tangential disposition occurs. ${ }^{5,6}$ This may preserve the precise optics of the cornea by imparting stability at the limbus, a zone of abrupt curvature change between the sclera and cornea. Because the organization of corneal collagen is critical to the maintenance of the shape of the cornea, some modification is to be expected in

From the ${ }^{1}$ School of Optometry and Vision Sciences, Cardiff University, Cardiff, United Kingdom; ${ }^{2}$ Moorfields Eye Hospital, London, United Kingdom; the ${ }^{3}$ Department of Ophthalmology, Great Wall Hospital of PLA, Beijing, Peoples Republic of China; and the ${ }^{4}$ Nuffield Department of Ophthalmology, University of Oxford, Oxford, United Kingdom.

Supported by Grant 0055710 from The Wellcome Trust and Grant G0001033 from the Medical Research Council.

Submitted for publication October 25, 2004; revised January 14, 2005; accepted January 18, 2005.

Disclosure: K.M. Meek, None; S.J. Tuft, None; Y. Huang, None; P.S. Gill, None; S. Hayes, None; R.H. Newton, None; A.J. Bron, None

The publication costs of this article were defrayed in part by page charge payment. This article must therefore be marked "advertise$m e n t "$ in accordance with 18 U.S.C. $\$ 1734$ solely to indicate this fact.

Corresponding author: Keith M. Meek, School of Optometry and Vision Sciences, Cardiff University, Redwood Building, King Edward VII Avenue, Cardiff CF10 3NB, UK; meekkm@cf.ac.uk. disorders such as keratoconus, in which the shape is compromised.

Keratoconus is the commonest dystrophy of the cornea, with an incidence of approximately 50 to 230 per 100,000 of the population. ${ }^{7,8}$ It is a frequent indication for keratoplasty in the United Kingdom (20\% compared with 38\% for endothelial failures $^{9}$. Keratoconus is characterized by a progressive thinning and ectasia of the central cornea that causes myopia and irregular astigmatism. A rigid contact lens can restore useful vision in many patients, but in advanced disease a corneal graft may be necessary.

$\mathrm{X}$-ray scattering (diffraction) is a powerful technique in which an intense beam of $\mathrm{x}$-rays is passed through the tissue to produce a scattering pattern consisting of one or more reflections where constructive interference of the scattered beam occurs. The distribution of the scattered x-rays can then be used to determine quantitatively the gross orientation of all the collagen fibrils in the path of the x-ray beam-that is, in the full thickness of the tissue. Figure 1 shows how a beam of $x$-rays is scattered by an array of identical collagen fibrils with a distribution of angular orientations in the plane at right angles to the beam's direction. The scattered $\mathrm{x}$-rays from fibrils oriented in a given direction produce a so-called equatorial reflection at right angles to the collagen fibril axes. The intensity of the reflection is proportional to the mass of fibrils oriented in that direction and falling in the path of the x-ray beam. Thus, if fibrils were arranged equally at all angles in the plane perpendicular to the x-ray beam, the reflection would be a ring of uniform intensity. If there were a distribution of fibrils around a single preferred orientation, the reflection would be two symmetrical arcs-the degree of arcing being quantitatively related to the angular spread in the fibril direction.

Using x-ray scattering, Daxer and Fratzl ${ }^{4}$ demonstrated that in advanced keratoconus the angle between the preferred collagen orientations at the center of the cone were altered from $90^{\circ}$ and $180^{\circ}$ to $60^{\circ}$ and $120^{\circ}$ - evidence that the structural change in these corneas is related to large-scale changes in the directions of the collagen lamellae. Improvements in high-intensity synchrotron $\mathrm{x}$-ray sources have resulted in faster data collection times and have now made it feasible to map in great detail the preferred directions of the collagen lamellae in corneal buttons, as well as the relative distribution of collagen fibril mass. We used these techniques to compare collagen orientation and the distribution of fibrillar mass in normal and keratoconus corneas.

\section{Methods}

\section{Tissues}

Two corneal buttons were obtained after penetrating keratoplasty for keratoconus and were marked for purposes of orientation. Neither patient had a history of acute corneal hydrops or other significant eye disease. Cornea A was a 7.75-mm button from a 49-year-old man with advanced keratoconus of the left eye, with an apical scar and irregular keratometry $(<6.0 \mathrm{~mm})$. The apex of the cone was displaced slightly inferiorly relative to the center of the cornea, but there was no 


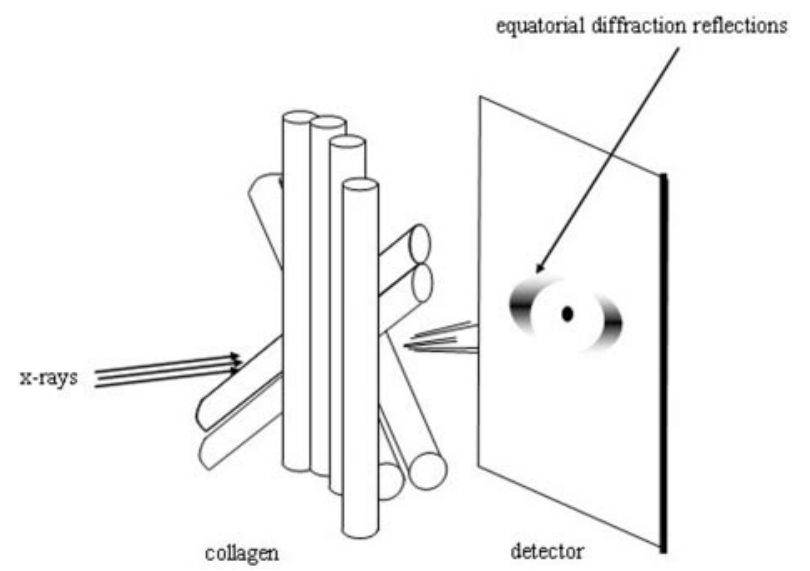

FigURE 1. A beam of parallel $x$-rays scattered by an array of collagen fibrils with different orientations within a plane perpendicular to the direction of the incident $\mathrm{x}$-ray beam. At small angles, as shown, the equatorial $x$-ray scattering arises from the distribution of collagen fibrils, and at wide angles it arises from the distribution of collagen molecules within the fibrils?; but, because the constituent collagen molecules are arranged approximately parallel to the fibril axis, for the present purposes, molecular orientation is a good approximation of fibril orientation.

peripheral thinning. Cornea B was a 7.5 -mm button from a 28 -year-old man who had a 13-year history of keratoconus. There was an apical cone with a small apical corneal scar. There was high astigmatism with right eye keratometry of $5.8 \mathrm{~mm}$ at $10^{\circ}$ and $<5.5 \mathrm{~mm}$ at $110^{\circ}$ (normal, $\sim 7.6 \mathrm{~mm}$ ). Unfortunately, no videokeratography was available. A normal left human cornea with scleral rim attached was obtained from the CTS Eye Bank (Bristol, UK) and was equilibrated to physiological hydration, as described previously. ${ }^{5}$ The central, $7.75-\mathrm{mm}$ button was trephined for comparison with the pathologic corneal buttons. The keratoconus buttons and normal cornea used in the present study were treated similarly, by being tightly wrapped in clinging film to prevent evaporation and stored at $-80^{\circ} \mathrm{C}$ until x-ray examination. All donors had given permission to use their tissues for research. Tissue procurement and use was in accordance with the Declaration of Helsinki and local regulations.

\section{X-ray Data Collection}

Each cornea was mounted in an air-tight Perspex cell, in which the humidity was maintained during the lengthy exposure to the $\mathrm{x}$-ray beam (approximately 20 hours). Tissue hydration was measured before and after the experiment and was found to have decreased by $<1 \%$. Irradiation was performed at the synchrotron radiation source (SRS; Daresbury, UK). The specimens were examined at Station 7.2 by a beam with a $0.1-\mathrm{mm}$ diameter cross section, a camera length of $12 \mathrm{~cm}$, and an x-ray wavelength of $0.1488 \mathrm{~nm}$. The specimen cell was mounted on a translation stage that could be moved both horizontally and vertically, either manually or by means of a stepper motor. With exposures of 30 seconds, scattering patterns were collected on an image plate detector (Mar Research, Hamburg, Germany) at each point across a $0.25 \times 0.25-\mathrm{mm}$ grid, to give nearly $800 \mathrm{x}$-ray patterns per specimen. Scattering from noncollagenous components of the tissue was subtracted, and the patterns were normalized to take account of fluctuations in $\mathrm{x}$-ray beam intensity. ${ }^{5}$

\section{Analysis of X-ray Data}

Figure $2 \mathrm{a}$ shows a wide-angle $\mathrm{x}$-ray pattern from a region of a keratoconus cornea where collagen fibrils were preferentially aligned mainly in one direction. The pattern consists of an x-ray reflection that takes the form of equatorial arcs, indicating in this case a spread of fibril axis orientations about the vertical direction. Starting at $0^{\circ}$ at the left of the reflection, the intensity of the scattered $\mathrm{x}$-rays was measured as a function of angle. The result is the intensity distribution shown in Figure $2 \mathrm{~b}$. This distribution contains three types of information about the fibril orientations. The total area under the graph (the total scattered intensity) is proportional to the total mass of fibrillar collagen in the path of the $x$-ray beam. This has two components, represented by a

FIGURE 2. (a) Wide-angle x-ray pattern from near the cone of a keratoconus cornea. The white spot at the center is the shadow of a lead beamstop used to suppress the intense unscattered x-ray beam. (b) Integrated intensity as a function of angle around the reflection. The scatter intensity can be divided into two components. Nonaligned scattering (shaded area) comes from a population of fibrils equally distributed in at all angles within the plane of the cornea. Aligned scattering (clear area) comes from a population of fibrils that have a preferential orientation within the plane of the cornea. After removal of the nonaligned component and the application of a $90^{\circ}$ phase shift to account for the fact that $\mathrm{x}$-ray equatorial reflections occur at right angles to the fibril or molecular axis, the data in (b) are plotted as a polar plot (c). Asymmetry in this plot shows the preferred orientation of the collagen averaged throughout the tissue thickness at the position through which the $\mathrm{x}$ rays pass.

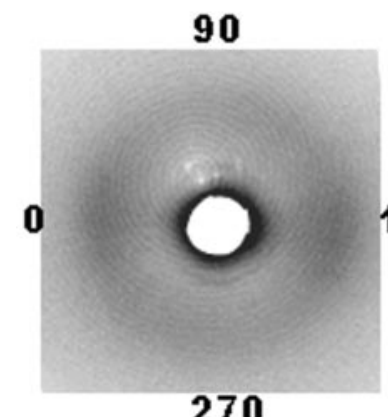

b
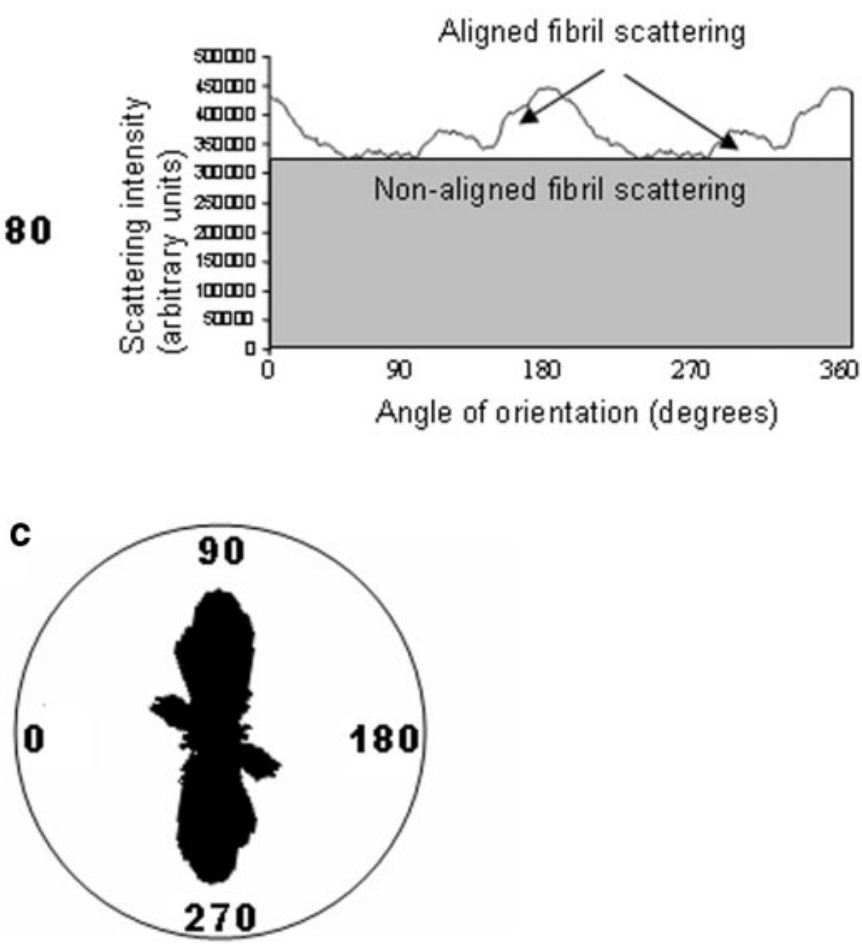
the shaded and unshaded areas. The shaded area represents the part of the scattering arising from the nonaligned (isotropic) fibrils-that is, fibrils that occur in equal numbers in all directions within the plane of the cornea. The unshaded area represents the contribution from the additional population of fibrils that take up a preferred orientation in the tissue (preferentially aligned fibrils). It is thus possible to use these areas as relative measures of the total aligned and nonaligned collagen in the $\mathrm{x}$-ray beam path. Each pattern was analyzed to produce a value for total scattering, aligned scattering, and isotropic scattering at that point. These values were used to produce two-dimensional contour plots that demonstrated how each of the parameters varied across the corneas. It should be noted that, in practice, the $\mathrm{x}$-ray beam traverses the slightly curved corneal buttons in a direction parallel to the optical axis, so that the measurements obtained represent a projection of the tissue onto a two-dimensional plane at right angles to the direction of the $\mathrm{x}$-ray beam.

The $\mathrm{x}$-ray pattern in Figure $2 \mathrm{a}$ also contains information about the distribution in the spread of the axes of the preferentially aligned fibrils. To represent this angular distribution of fibrils, the following procedure was performed. First, the nonaligned fibril scatter was removed (i.e., the shaded part of the graph in Fig. 2b was subtracted, leaving only the unshaded area). This left the distribution of x-ray intensity as a function of angle for only the preferentially aligned fibrils. This distribution was then converted into a polar (vector) plot (Fig. 2c), taking into account the fact that the $\mathrm{x}$-ray intensity appears at right angles to the fibril axis. ${ }^{10,11}$ The radial length of the polar plot at a given angle is directly proportional to the mass of collagen fibrils aligned at that angle. The overall size of the plot is therefore related to the total mass of aligned collagen, and the asymmetry gives an indication of the preferential direction(s) of this collagen. Thus, in this example, most preferentially aligned fibrils run vertically and none run horizontally. Polar plots were produced from the scattering patterns obtained from each point on the grid, and these plots were then assembled as a montage to show how the preferred collagen orientation varies across the normal and the keratoconus corneal buttons.

\section{Results}

We used the techniques described herein to examine normal corneas between 25 and 86 years of age, and the results (not shown) were essentially the same as that presented for the button chosen as the control for the study. Figure $3 a$ is the collagen orientation map for this control button. Each constituent polar plot shows the preferred directions of the collagen fibrils at that point in the tissue. The control cornea shows the two preferred, orthogonal orientations of lamellae throughout most of the button. This arrangement is shown by the crossshaped polar plots, indicating collagen preferentially aligned in the vertical and horizontal directions. The plots are smaller in the central part where the cornea is thinner, as there are fewer collagen fibrils in the path of the x-ray beam. Note the lack of an orthogonal arrangement toward the edge of the figure. Although the possibility of some edge effects produced by the trephining process cannot be excluded, it is known that outside the central $7 \mathrm{~mm}$ (i.e., toward the edge of the excised button), additional fibrils cross the cornea and swamp the contribution from the orthogonal lamellae. ${ }^{12}$

Figure $3 \mathrm{~b}$ shows the map of preferred collagen orientations in keratoconus button $\mathrm{A}$. The inferior-superior and nasaltemporal preferred orientations in the normal cornea are absent in the tissue, except at the temporal side, indicating rearrangement of lamellar orientations across much of the corneal button. The region of the cone is clearly visible just below the center of the montage. Figure 4 shows the map of preferred collagen orientation from keratoconus sample $B$. Again, many lamellae appear to have been displaced from the normal orthogonal arrangement into other directions leading to severe disruption of the collagen orientation throughout the button. In Figures $3 \mathrm{~b}$ and 4, there is evidence that the lamellae tend to curve around or are tangential to the edge of the cone.

Contour plots of total and preferentially aligned collagen from the two keratoconus buttons and the normal button are presented in Figure 5. The normal cornea shows a fairly regular increase in collagen mass from the center outward (Fig. 5a). This reflects the increasing thickness as one moves outward from the central cornea (compounded by the slight curvature of the cornea). Figures $5 \mathrm{~b}$ and $5 \mathrm{c}$ show the positions of the keratoconus cones, where the amount of collagen is greatly reduced. Figures $5 \mathrm{~d}$, $5 \mathrm{e}$, and $5 \mathrm{f}$ show the distribution of preferentially aligned collagen in the three corneas. In the normal cornea, the preferentially aligned collagen did not follow the same distribution pattern as the total collagen and, in particular, preferentially aligned collagen increased at the edge of the button in the four quadrants, to form a diamond shape in the center. This pattern is characteristic of normal human corneas and is likely to be due to the presence of additional anchoring lamellae that traverse and hence contribute to the increased thickness of the peripheral cornea. ${ }^{12}$ Nevertheless, the amount of preferentially aligned collagen is relatively uniform throughout the central (prepupillary) cornea. The preferentially aligned collagen in keratoconus (Figs. 5e, 5f), in contrast, showed much more variation than normal. The uniformity across the central cornea was lost, with regions of more highly aligned collagen intermixed with regions in which there was little aligned collagen. There appeared to be a gross distortion of the normal diamond-shaped distribution of peripherally oriented fibrils.

It would be of interest to compare the total and aligned scatter summed across each of the corneas. However, because scattering increases away from the central cornea and because of the unknown edge effects of the trephining process, it is safer to consider just the central parts of the buttons. Table 1 shows the relative scatter from the central $20 \mathrm{~mm}^{2}$. It is striking that, despite the considerable thinning that occurred in part of the keratoconus corneas, the total scatter was reduced by only a few percentage points and, across the button as a whole, the proportion of aligned scatter remained fairly constant at approximately $30 \%$. These data support the view that much of the thinning that occurs in keratoconus is due to redistribution of fibrillar collagen.

\section{Discussion}

For technical reasons, it was not possible to perform the experiments in this study by keeping the x-ray beam normal to the surface of the cornea during the whole mapping procedure, and so the beam and cornea are only at right angles at the center of the cornea. Elsewhere the cornea is effectively tilted by a variable angle, $\theta$. The relationship is

$$
V_{\mathrm{k}}=V_{\mathrm{n}}\left(t_{\mathrm{k}} \cos \theta_{\mathrm{n}} / t_{\mathrm{n}} \cos \theta_{\mathrm{k}}\right),
$$

where $V$ is the sampled volume, $t$ the tissue thickness, $\theta$ the angle of tilt, and the subscripts $\mathrm{n}$ and $\mathrm{k}$ are keratoconus and normal, respectively. Maintaining the beam parallel to the optical axis thus has the effect of increasing the volume of tissue sampled by the beam as one moves farther from the center of the cornea. This, in turn, means that corneal thickness and mass will be overestimated in the steeper regions of the buttons. We have estimated the effect of this curvature for normal and moderate/severe keratoconus ( $55 \mathrm{D})$, both geometrically and from photographic images, and both methods showed that the ratio $\cos \theta_{\mathrm{n}} / \cos \theta_{\mathrm{k}}$ has a maximum value of approximately 


\section{a) Control}

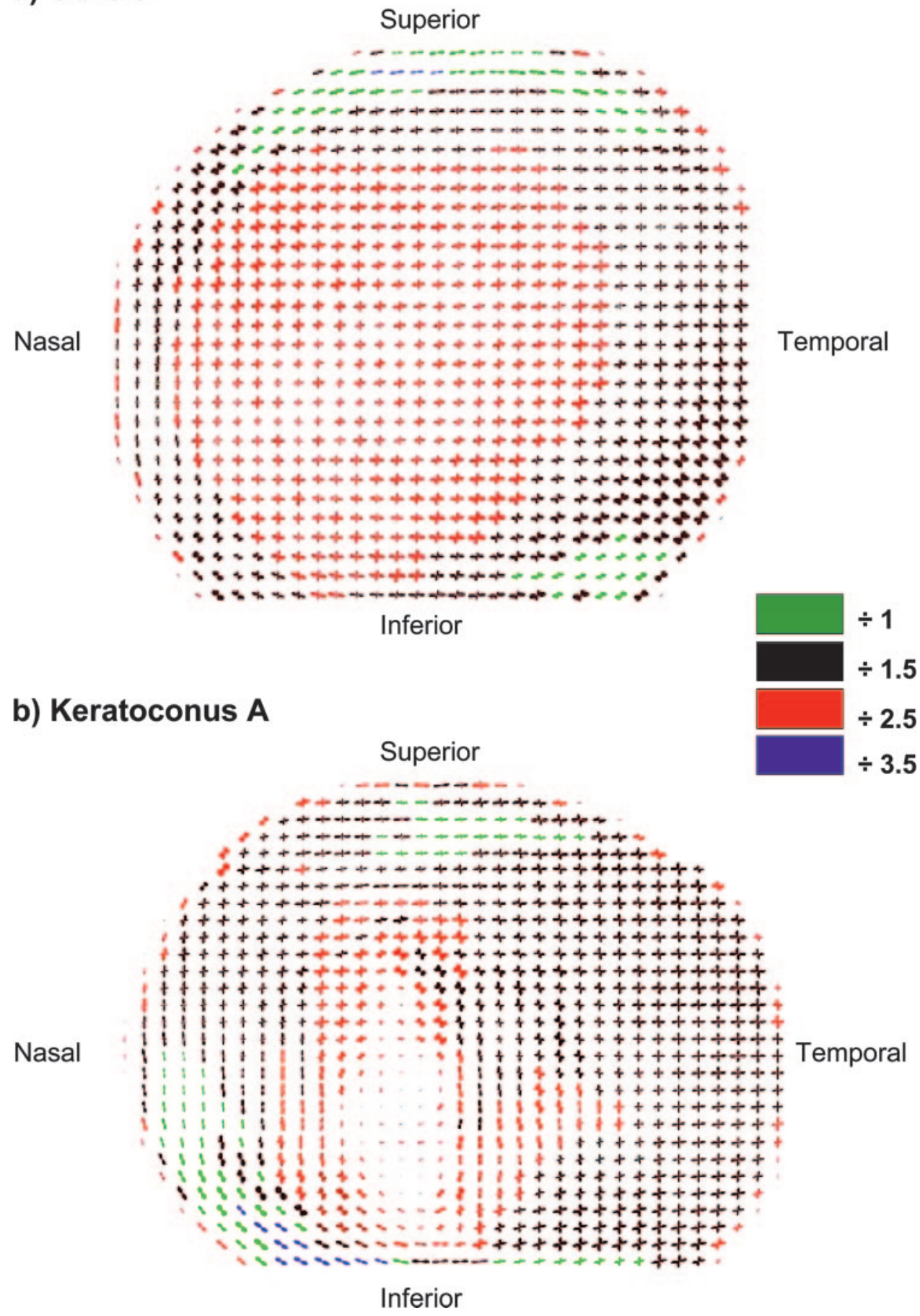

FigURE 3. The preferred fibril direction across (a) the normal corneal button and (b) keratoconus button A. The scale of the individual polar plots was chosen so that the shape of those in the thinnest part of the cornea could just be discerned. As a consequence, plots in other regions were too large to fit in the montage and so were scaled down by the factors indicated by the color key. The cross-shaped symbols across most of the normal button indicate vertical and horizontal preferred orientations. In the keratoconus button, the region of greatest thinning was elongated vertically, and contained the least aligned collagen. There is also the suggestion that the cone was subdivided into two more circular regions. There were large, local variations in the sizes of the plots, probably arising from thinning and a focal increase in area (i.e., ectasia).
1.06 , indicating an oversampling of the keratoconus button of $\sim 6 \%$ at its steepest position.

Two chief mechanisms for the development of keratoconus have been put forward. One proposes that ectasia is closely associated with tissue degradation or reduced maintenance, ${ }^{13}$ whereas the other suggests that it is due to slippage between collagen fibrils, ${ }^{14}$ with no overall tissue loss. These concepts are not mutually exclusive, since enzymatic degradation could permit slippage between collagen fibrils.

The x-ray data presented herein, extend the findings of Daxer and Fratzl, ${ }^{4}$ indicating a gross rearrangement of vertical and horizontal collagen lamellae in keratoconus. We have provided evidence that many of the posterior lamellae are displaced, particularly near the presumed apex of the cone and that changes can occur at least to the edge of the excised buttons. The total scattering contour maps in Figures $5 \mathrm{a}, 5 \mathrm{~b}$, and $5 \mathrm{c}$ show that, in keratoconus, there is a very uneven distribution of collagen, with no circular symmetry in the center of the cornea. Similarly, a distortion of the peripheral diamond-shaped pattern of anchoring lamellae, suggests a redistribution of preferentially aligned collagen at the periphery of the button (Figs. $5 \mathrm{~d}, 5 \mathrm{e}, 5 \mathrm{f}$ ). This change in fibril orientation is difficult to explain on the basis of tissue degradation alone, since collagen loss would be unlikely to give rise to a systematic realignment of fibrils. In our opinion, it is more readily explained in terms of collagen fibril 


\section{Keratoconus B}

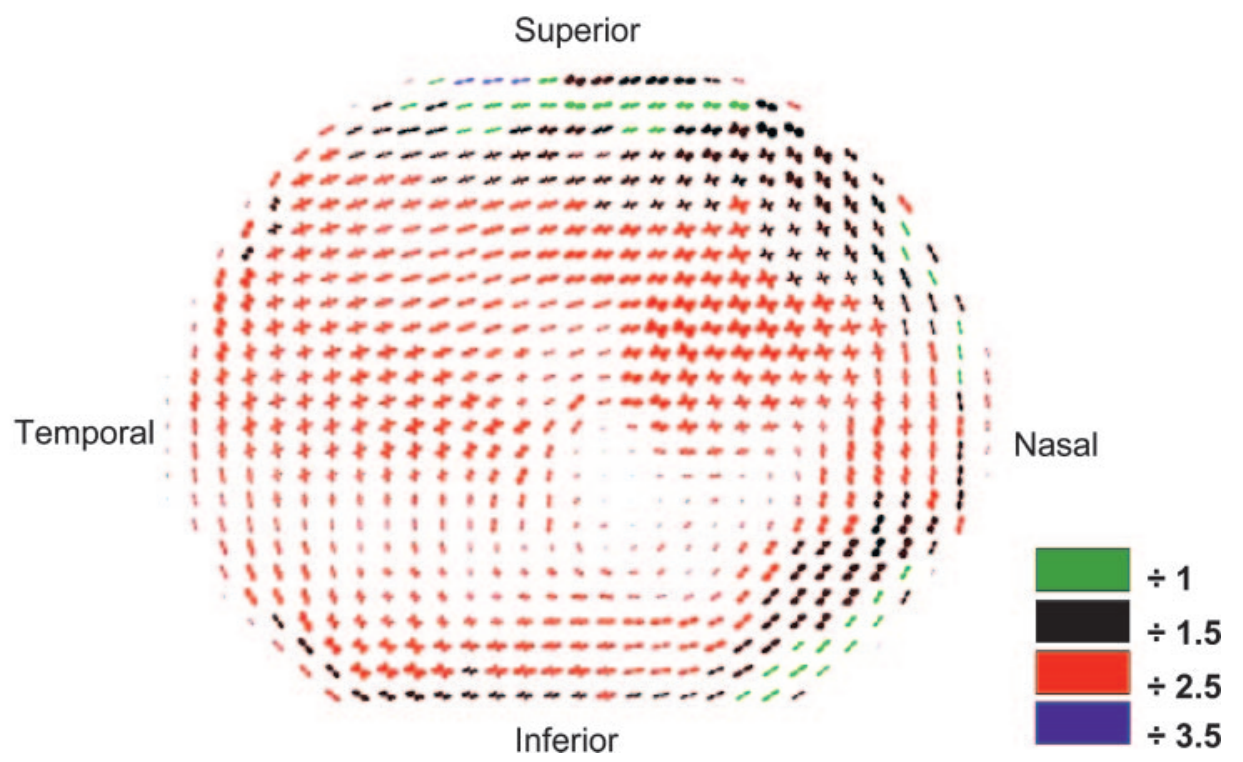

FIGURE 4. The preferred fibril direction across keratoconus button $\mathrm{B}$. Plots were scaled down to fit on the montage, by using the factors in the color key. The angle between the preferred lamellar directions varied considerably in different parts of the sample. slippage, perhaps in conjunction with a process of remodeling.

Any explanation for the mechanism of keratoconus must account for the altered profile of the keratoconus cornea, in the apparent absence of breaks in the collagen bundles. To understand how the ordered lamellar arrangement of the corneal stroma may give rise to the disrupted pattern found in keratoconus, it is necessary to review normal corneal structure. In the posterior two thirds of the human cornea, lamellae lie in the plane of the cornea and run without interruption from limbus to limbus with a limited anteroposterior interweave. ${ }^{15-18}$ At the limbus, the collagen fibrils pursue a circular or pseudocircular course. The term pseudocircular implies that, although fibrils enter the limbus tangentially, their precise origins are unknown. Although the preferred direction of the posterior lamellae is in the inferior-superior and nasal-temporal directions, the lamellae of the anterior stroma have little preferred meridional arrangement. ${ }^{3}$ In the anterior stroma, there is an extensive anteroposterior interweave, and a proportion of the lamellae that arise in the limbus insert into the region of Bowman's layer. ${ }^{18-30}$ This arrangement is thought to be essential for the maintenance of corneal shape. ${ }^{31,32}$

The anterior lamellae often split in both a lateral and an anterior-posterior direction. ${ }^{29,33,34}$ Studies from our laboratory $^{6,12}$ and elsewhere ${ }^{29,34}$ indicate that many corneal lamellae do not course straight across the cornea from limbus to limbus, but rather follow a less direct route. Scanning electron microscopy of normal corneas revealed frequent instances when lamellae split into two narrower lamellae (Fig. 6a), which may subsequently fuse with lamellae running in a different direction. ${ }^{29}$ The constituent collagen fibrils within these lamellae are therefore somewhat longer than they would have to be if they were to follow a more direct route. The points at which lamellae split ${ }^{35}$ are potentially weak, and rely on interfibrillar forces to maintain cohesion (Fig. 6b). Surgical dissection of the corneal stroma is not resistance free, even posteriorly where there is less anteroposterior interweave, suggesting that there are other elements that bind the collagen lamellae together. ${ }^{36}$ Part of this resistance is due to interactions between the collagen fibrils (e.g., type III and heteromeric type I and V collagens) and other matrix proteins, such as the proteoglycans, ${ }^{37,38}$ dermatopontin, ${ }^{39}$ and type VI collagen. ${ }^{40}$ Type VI collagen acts as a bridge between type I collagen fibrils ${ }^{41}$ and also interacts with keratan sulfate proteoglycans (lumican, keratocan, and mimecan), decorin (the dermatan sulfate proteoglycan), ${ }^{42-44}$ hyaluronan, ${ }^{45}$ and keratoepithelin, or TGF $\beta$-induced protein. ${ }^{46}$ Keratocytes may also play some role in stabilizing adjacent lamellae. Most of the stromal keratocytes lie between the lamellae and interact with each other via long processes and with the collagen on either side. In this respect, it is interesting that differences in keratocyte surface components, cell morphology and cell-matrix interactions have all been reported in keratoconus. ${ }^{47,48}$

If this "interfibrillar glue" were weakened, then lamellae (or collagen bundles) would have the potential to tear apart, ${ }^{14}$ just as a nick, cut into the edge of a piece of material propagates into a tear when a certain tension is exceeded. This would result in a displacement of lamellae and a redistribution of collagen locally, as we have reported herein. The central and inferior regions of the cornea are likely to be affected preferentially (the main region of cone formation), since interlamellar cohesive strength is at a minimum in that area in normal cornea. ${ }^{49,50}$

Many of the clinical features of keratoconus can be explained by a biomechanical hypothesis, which proposes that corneal thinning and ectasia is the result of an interlamellar and an interfibrillar slippage of collagen within the stroma, due to a loss of cohesion between collagen fibrils and the noncollagenous matrix. ${ }^{4,14,49-54}$ Lamellar slippage in the posterior stroma would require a release of lamellae from their peripheral location at the limbus, as well as a loss of cohesion along the length of the lamellae. Unraveling of corneal lamellae (or of individual fibrils) from the limbus, and/or throughout the cornea would account for the lateral rearrangement of lamellae. This unraveling would also increase the effective length of lamellae, thus releasing tension on the fibrils and allowing deformation. For the anterior lamellae, unraveling could imply, in addition, the disinsertion of lamellae from their anchoring sites in Bowman's layer.

Thinning is a presenting finding in keratoconus ${ }^{54}$ and Edmund ${ }^{52}$ demonstrated that, except in advanced keratoconus, the cross-sectional area of corneas in optical section did not differ from that of normal corneas. This implies that ectasia occurs by a redistribution of stromal mass, rather than by a loss from extensive tissue degradation. While Edmund found no direct evidence that lamellae are released from their limbal 


\section{Total}

Normal

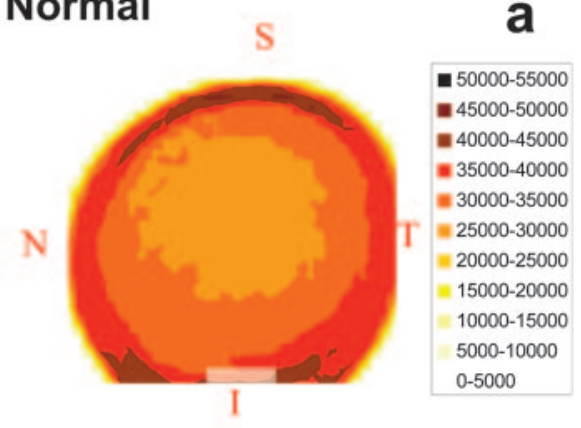

\section{Aligned}

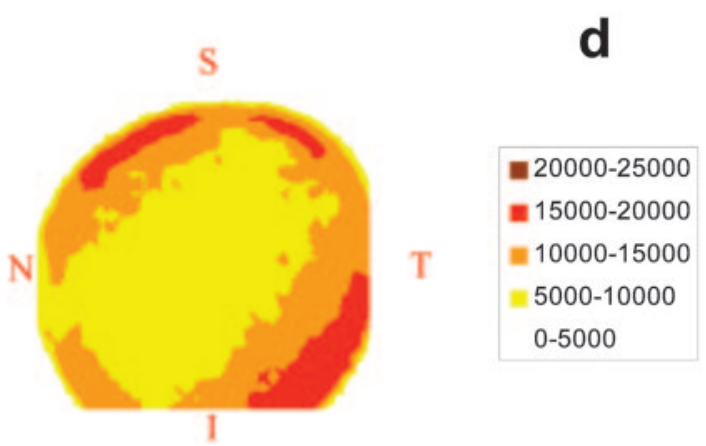

\section{Keratoconus A}

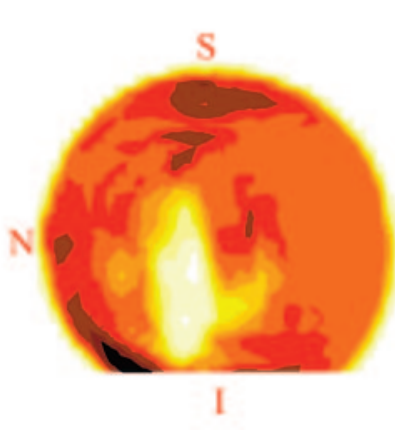

b
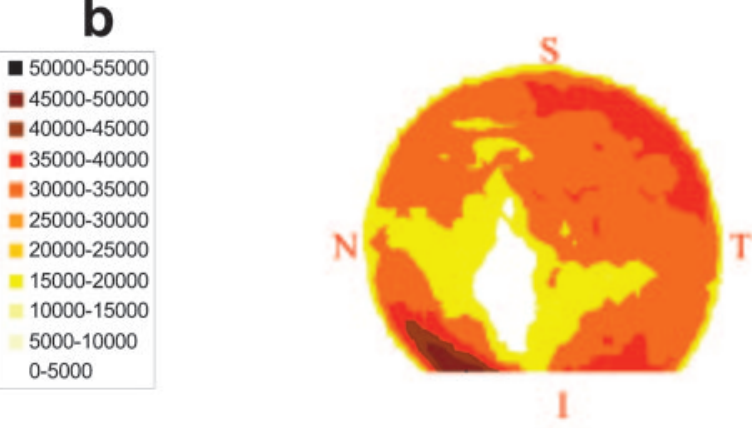

e

30000-35000

- 25000-30000

- 20000-25000

-15000-20000

=10000-15000

$5000-10000$

0-5000

\section{Keratoconus B}
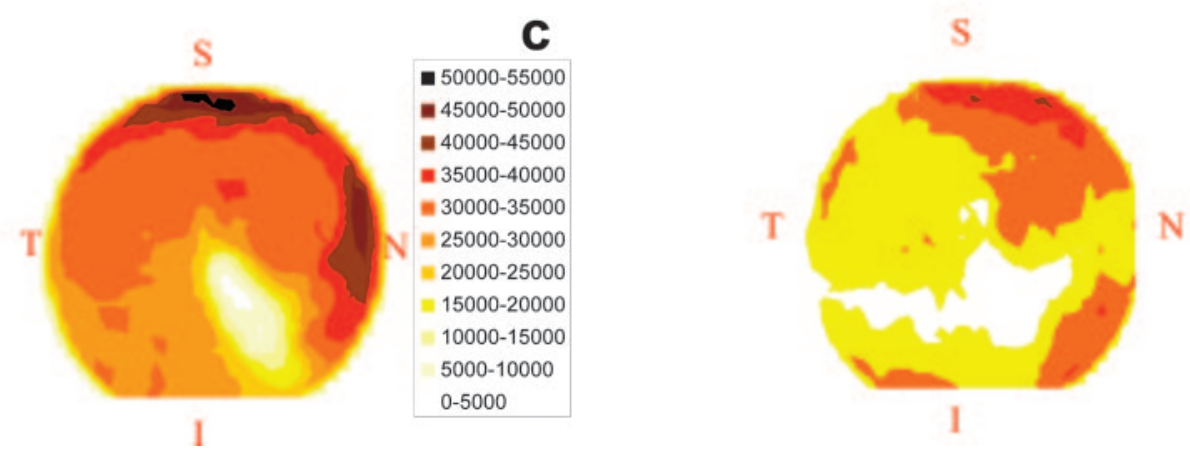

f

20000-25000

- 15000-20000

$=10000-15000$

5000-10000

$0-5000$

FiguRE 5. Scattering-intensity maps from the corneal buttons. (a), (b), and (c) are the total scatter (arbitrary units) and (d), (e), and (f) are the aligned scatter (same arbitrary units). The superior (S) inferior (I), nasal (N) and temporal (T) sides of each button are indicated.

location, ${ }^{55}$ Owens and Watters ${ }^{56}$ showed that thickness was reduced outside the cone. Measuring $4 \mathrm{~mm}$ from the center, they found a significant reduction of (5.8\%) superiorly, (6.9\%) superotemporally, (13.8\%) inferotemporally, (9.4\%) inferonasally, and (8.2\%) nasally. There was a $7.6 \%$ reduction in thickness inferiorly, $5.6 \mathrm{~mm}$ from the corneal center. ${ }^{56}$

Processes that lead to a lengthening of stromal collagen lamellae without rupture must be assumed to occur physiologically in the developing eye with prenatal corneal growth. This could come about in different ways. Birk et al. ${ }^{57}$ established that in chick tendon and cornea, collagen fibrils grow by a process of interstitial extension, due to fusion of fibril "segments" which increase in length over time (e.g., 10-30 $\mu \mathrm{m}$ in the 14-day-old tendon and $>60 \mu \mathrm{m}$ in the 18-day-old tendon). ${ }^{57-59}$ For the cornea, it cannot be excluded too, that remodeling includes fibril end-lengthening and fibril slippage before cessation of growth. We hypothesize that one mechanism for keratoconus could be that the physiological events

TABLE 1. Relative X-Ray Scatter from the Central $20 \mathrm{~mm}^{2}$ of the Corneal Buttons

\begin{tabular}{lccc}
\hline \multicolumn{1}{c}{ Specimen } & $\begin{array}{c}\text { Total } \\
\text { Scatter* }\end{array}$ & $\begin{array}{c}\text { Aligned } \\
\text { Scatter* }\end{array}$ & $\begin{array}{c}\text { Ratio of Aligned } \\
\text { to Total Scatter } \\
\text { (\%) }\end{array}$ \\
\hline Normal & 100 & 100 & 30 \\
Keratoconus A & 96 & 108 & 34 \\
Keratoconus B & 93 & 88 & 29 \\
\hline
\end{tabular}

* Data are expressed as a percentage of normal. 
a

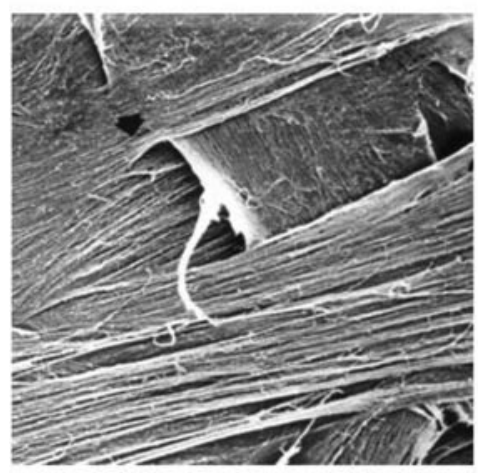

b

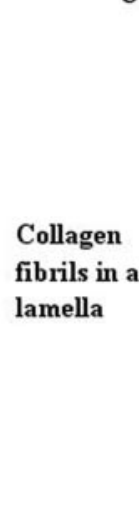

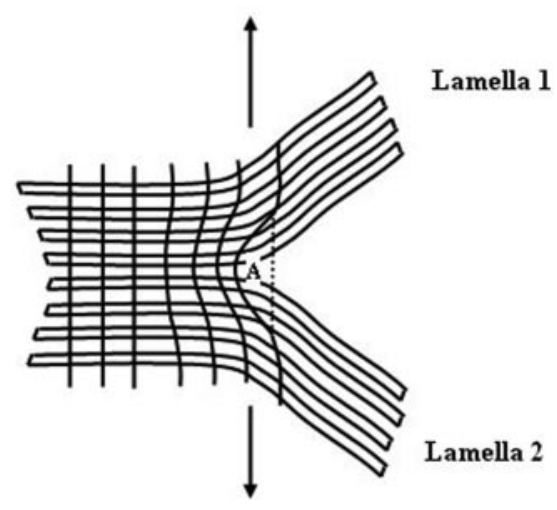

Figure 6. Collagen fibrils in a region where a lamella splits into two separate lamellae. In the scanning electron micrograph (a) (courtesy Wolfgang Radner, Dept. of Ophthalmology, University of Vienna), a lamella splits (near the arrowhead) and, in this case, interweaves with a lamella running in a different direction. (b) A simplified (two-dimensional) representation of the stress pattern near the split. The stress is equal in all directions within the plane of the diagram (which actually represents the curved plane of the cornea), but it is only the component at right angles to the lamellae that is indicated, as this is the force that tends to tease apart the fibril bundles. In the normal cornea, this stress must be withstood by the interfibrillar matrix. Strain is relieved only in the region immediately around the split (A). This means that the stress trajectories (the black lines in the
diagram that may be thought of as the paths along which stress is "handed on" from fibril to fibril in the tissue) are concentrated in the neighborhood of the apex of the split. Any reduction in the cohesive forces exerted by the interfibrillar matrix will initially have an effect on points such as (A), possibly causing the lamellae to separate.

that would normally "lock" the corneal and limbal lamellae in place during childhood, fail to switch in. This is likely to be under genetic control and could explain the slow evolution of keratoconus from childhood and the early teens.

In addition to these biomechanical events, there is an extensive body of literature supporting the occurrence of biochemical changes within keratoconus corneas. The concept of tissue degradation, based on the study of keratoplasty buttons, depends on the demonstration of collagen loss and proteoglycan changes in affected corneas and on the upregulation of degradative enzymes. ${ }^{60-63}$

Zhou et al. ${ }^{64}$ reported increased cathepsin-B and $-G$ and gelatinase and caseinase activity in keratoconus corneas, and Sawagamuchi et al. ${ }^{65}$ found focal alterations in enzyme activity in relation to breaks in Bowman's layer that would favor tissue breakdown. A defect in glycoprotein synthesis was reported in earlier studies $^{66}$ and numerous workers have reported an abnormal electron-dense material in the stroma. ${ }^{35,67-73}$ Various investigators have variously found an increase, ${ }^{73}$ a reduction, ${ }^{74}$ or no change $\mathrm{e}^{61,75}$ in proteoglycans. The proteoglycans decorin and keratocan have been reported to be upregulated in keratoconus, ${ }^{76,77}$ whereas the glycosaminoglycan keratan sulfate is reduced in amount and possibly downregulated. ${ }^{78-80}$

In summary, we have shown that in keratoconus, formation of the cone is associated with displacement of the axes of the collagen fibrils and distortion of the orthogonal matrix. This implies a degree of lamellar fluidity and slippage. We propose that the displacement and redistribution are primarily caused by an unraveling of lamellae, along their length and from their limbal anchors, and a teasing apart at points where lamellae bifurcate and from Bowman's layer. This alteration could result from the failure of a "locking mechanism" normally established in infancy and childhood, or from the effects of enzymatic digestion. We contend that in keratoconus, an as yet unidentified primary event, ${ }^{13}$ which may be under genetic control, triggers a breakdown of the "glue" that stabilizes collagen fibrils and facilitates the process of lamellar or fibrillar slippage that we describe herein. This hypothesis has therapeutic implications, and it is relevant that attempts are being made to slow down the progression of keratoconus by enhancing stromal cross-linking. Some success has been claimed recently for a photosensitizing regimen in which cross-linking is enhanced by exposing the eye to UVA after the application of topical riboflavin drops (Sandner D, et al. IOVS 2002;43:ARVO E-Abstract 2887). ${ }^{81}$

\section{Acknowledgments}

The authors thank the support staff at the Synchrotron Radiation Source at Daresbury for help with the x-ray data collection, and the CTS Eye Bank (Bristol, UK) for providing the normal cornea.

\section{References}

1. Maurice DM. The structure and transparency of the cornea. J Physiol (Lond). 1957;136:263-286.

2. Donohue DJ, Stoyanov BJ, McCally RL, Farrell RA. Numerical modeling of the cornea's lamellar structure and birefringence properties. J Opt Soc Am A Opt Image Sci Vis. 1995;12:1425-1438.

3. Meek KM, Blamires T, Elliott GF et al. The organisation of collagen fibrils in the human corneal stroma: a synchrotron $\mathrm{x}$-ray diffraction study. Curr Eye Res. 1987;6:841-846.

4. Daxer A, Fratzl P. Collagen fibril orientation in the human corneal stroma and its implications in keratoconus. Invest Ophthalmol Vis Sci. 1997;38:121-129.

5. Newton RH, Meek KM. Circumcorneal annulus of collagen fibrils in the human limbus. Invest Ophthalmol Vis Sci. 1998;39:11251134 .

6. Newton RH, Meek KM. The integration of the corneal and limbal fibrils in the human eye. Biophys J. 1998;75:2508-2512.

7. Krachmer JH, Feder RS, Belin MW. Keratoconus and related noninflammatory corneal thinning disorders. Surv Ophthalmol. 1984; 28:293-322.

8. Rabinowitz YS. Keratoconus. Surv Ophthalmol. 1998;42:297-319.

9. Vail A, Gore SM, Bradley BA, et al. Corneal transplantation in the United Kingdom and Republic of Ireland. Br J Ophthalmol. 1993; 77:650-656.

10. Meek KM, Quantock AJ. The use of x-ray scattering techniques to determine corneal ultrastructure. Prog Ret Eye Res. 2001;96-137.

11. Connon CJ, Meek KM. Organization of corneal collagen fibrils during the healing of trephined wounds in rabbits. Wound Repair Regen. 2003;11:71-78.

12. Aghamohammedzadeh KM, Newton RH, Meek KM. X-ray scattering used to map the preferred collagen orientation in human cornea and limbus. Structure. 2004;12:249-256.

13. Kenney MC, Brown DJ, Rajeev B. Everett Kinsey Lecture. The elusive causes of keratoconus: a working hypothesis. CLAO J. 2000;26:10-13. 
14. Polack F. Contribution of electron microscopy to the study of corneal pathology. Surv Ophthalmol. 1976;20:375-414.

15. Kokott W. Das Spaltlinienbild der Sklera. Klin Monatsbl Augenbeilkd. 1934;92:117-185.

16. Kokott W. Über mechanisch-funktionelle Strukturen des Auges. Albrecht von Graefes Arch Ophthalmol. 1938;138:424- 485.

17. Smelser GK, Oszanics V. New concepts in anatomy and histology of the cornea. In: King JH, McTigue JW, eds. The Cornea World Congress. London; Butterworth, 1965:1-20.

18. Maurice DM. The cornea and sclera. In: Davson $\mathrm{H}$, ed. The Eye. 2nd ed. Vol. 1. New York: Academic Press, 1969:489-600.

19. Salzmann M. The Anatomy and Histology of the Human Eyeball in the Normal State: Its Development and Senescence. Chicago: University Chicago Press; 1912.

20. Polack FM. Morphology of the cornea. I. Study with silver stains Am J Ophthalmol. 1961;51:1051-1056.

21. McTigue JW. The human cornea: a light and electron microscopic study of the normal cornea and its alterations in various dystrophies. Trans Am Ophthalmol Soc. 1967;65:591-660.

22. Fine BS, Yanoff M. Ocular Histology: A Text and Atlas. 2nd ed. New York: Harper and Row; 1979.

23. Goldman JN, Benedek CH, Dohlman CH, et al. Light diffraction and scattering in swollen human corneas. Invest Ophthalmol. 1968;7: 501-519.

24. Bron AJ, Tripathi RC. The anterior corneal mosaic. Br J Physiol Opt. 1970;25:8-13.

25. Hogan MJ, Alvarado JA, Weddell JE. Histology of the Human Eye. Philadelphia: WB Saunders; 1971

26. Davson H. The Eye. New York: Academic Press; 1984. Vegetative Physiology and Biochemistry; Vol 1b.

27. Smolek MK, McCarey BE. Interlamellar adhesive strength in human eyebank corneas. Invest Ophthalmol Vis Sci. 1990;31:1087-1099.

28. Komai Y, Ushiki T. The three-dimensional organisation of collagen fibrils in the human cornea and sclera. Invest Ophthalmol Vis Sci. 1991;32:2244-2258.

29. Radner W, Zehetmayer M, Aufreiter R, et al. Interlacing and crossangle distribution of collagen lamellae in the human cornea. Cornea. 1998; 17:537-543.

30. Klyce SD, Beuerman RW. Structure and function of the cornea. In: Kaufman HE, Barron BA, McDonald MB, et al., eds. The Cornea. New York: Churchill Livingstone; 1989:3-28.

31. Müller LJ, Pels E, Vrensen GFJM. The specific architecture of the anterior stroma accounts for maintenance of corneal curvature. Br J Ophthalmol. 2001;85:437-443.

32. Bron AJ. The architecture of the corneal stroma. Br J Ophthalmol. 2001;85:379-383.

33. Radner W, Zehetmeyer M, Mallinger R, et al. Zur dreidimensionalen Anordnung der collagenen Lamellen im posterioren Stroma der menschlichen Hornhaut. Spektr Augenheilkd. 1993;7:77-80.

34. Radner W, Mallinger R. Interlacing of collagen lamellae in the midstroma of the human cornea. Cornea. 2002;21:598-601.

35. Pataa CL, Joyon L, Roucher F. Ultrastucture du keratocone. Arch Ophtalmol (Paris). 1970;80:403-418.

36. Maurice DM. Some puzzles in the microscopic structure of the stroma. J Refract Surg. 1996;12:677-683.

37. Meek KM, Elliott GF, Nave C. A synchrotron x-ray diffraction study of bovine cornea stained with cupromeronic blue. Collagen Relat Res. 1986;6:203-218.

38. Scott JE, Haigh M. Proteoglycan-Type I collagen fibril interactions in bone and non-calcifying tissues. Biosci Rep. 1985;5:71-81.

39. Nieduszynski IA, Brown GM, Ellis TS, et al. Dermatopontin interactions with keratan sulphate proteoglycans (abstract). Eighth Corneal Conference, Cardiff, Wales, UK 2004. Ophthalmic Res. 2004;36:285.

40. Hirano K, Kobayashi M, Kobayashi K, et al. Experimental formation of $100-\mathrm{nm}$ periodic fibrils in the mouse corneal stroma and trabecular meshwork. Invest Ophthalmol Vis Sci. 1989;30:869874 .

41. Cho HI, Covington, HI, Cintron C. Immunolocalization of type VI collagen in developing and healing rabbit cornea. Invest Ophthalmol Vis Sci. 1990;31:1096-1102.
42. Takahashi T, Cho HI, Kublin CL, et al. Keratan sulfate and dermatan sulfate proteoglycan associate with type VI collagen in fetal rabbit cornea. J Histochem. 1993;41:1447-1457.

43. Bidanset DJ, Guidry C, Rosenberg LC, et al. Binding of the protein decorin to collagen type VI. J Biol Chem. 1992;267:5250-5256.

44. Nakamura M, Kimura S, Kobayashi M, et al. Type VI collagen bound to collagen fibrils by chondroitin/dermatan sulfate glycosaminoglycan in mouse corneal stroma. Jpn J Ophthalmol. 1997; 41:71-76

45. Kielty CM, Whittaker SP, Grant ME, et al. Type VI collagen microfibrils: evidence for a structural association with hyaluronan. J Cell Biol. 1992;118:979-990.

46. Rawe IM, Zhan Q, Burrows R, et al. Beta-Ig: molecular cloning and in situ hybridization in corneal tissues. Invest Ophthalmol Vis Sci. 1997;38:893-900.

47. Rock ME, Moore MN, Anderson JA, Binder PS. 3-D computer models of human keratocytes. CLAO J. 1995;21:57-60.

48. Yue BY, Baum JL, Smith BD. Identification of collagens synthesised by cultures of normal human corneal and keratoconus stromal cells. Biochim Biophys Acta. 1983;755:318-325.

49. Smolek MK. Interlamellar cohesive strength in the vertical meridian of human eye bank corneas. Invest Ophthalmol Vis Sci. 1993; 34:2962-2969.

50. Smolek MK, Beekhuis WH. Collagen fibril orientation in the human corneal stroma and its implications in keratoconus. Invest Ophthalmol Vis Sci. 1997;38:1289-1290.

51. Bron AJ. Keratoconus: the Disease. $\mathrm{J} \mathrm{Br}$ Contact Lens Assoc. 1984;7:56-62.

52. Edmund C. Corneal tissue mass in normal and keratoconic eyes in vivo estimation based on area of horizontal optical sections. Acta Ophthalmol. 1988;66:305-308.

53. Fullwood NJ, Tuft SJ, Malik NS, et al. Synchrotron x-ray diffraction studies of keratoconus corneal stroma. Invest Ophthalmol Vis Sci. 1992;33:1734-1741.

54. Kerr-Muir MG, Woodward EG, Leonard TJ. Corneal thickness, astigmatism, and atopy. Br J Ophthalmol. 1987;71:207-211.

55. Edmund C. The corneo-limbal ring in normal and keratoconic eyes. Acta Ophthalmol. 1988;66:376-380.

56. Owens H, Watters GA. An evaluation of the keratoconic cornea using computerised corneal mapping and ultrasonic measurements of corneal thickness. Ophthalmic Physiol Opt. 1996;16: $115-123$.

57. Birk DE, Nurminskaya MV, Zycband EI. Collagen fibrillogenesis in situ: fibril segments undergo post-depositional modification resulting in linear and lateral growth during matrix development. Dev Dyn. 1995;202:229-243.

58. Birk DE, Hahn RA, Linsenmyer CY, et al. Characterization of fibril segments from chicken embryo cornea, dermis and tendon. $M a$ trix Biol. 1996;15:111-118.

59. Birk DE, Zycband EI, Woodruff S, et al. Collagen fibrillogenesis in situ: fibril segments become long fibrils as the developing tendon matures. Dev Dyn. 1997;208:291-298.

60. Kao WW, Vergnes JP, Ebert J, et al. Increased collagenase and gelatinase activities in keratoconus. Biochem Biophys Res Commun. 1982;107:929-936.

61. Rehany U, Lahav M, Shoshan S. Collagenolytic activity in keratoconus. Ann Ophthalmol. 1982;14:751-754.

62. Yue BYJT, Sugar J, Benveniste K. Heterogeneity in keratoconus: possible biochemical basis. Proc Soc Exp Biol Med. 1984;175:336341.

63. Collier SA. Is the corneal degradation in keratoconus caused by matrix-metalloproteinases? Clin Exp Ophthalmol. 2001;29:339334

64. Zhou L, Sawaguchi S, Twining SS, et al. Expression of degradative enzymes and protease inhibitors in corneas with keratoconus. Invest Ophthalmol Vis Sci. 1998;39:1117-1124.

65. Sawagamuchi S, Twinning SS, Yue BY, et al. Alpha 2 macroglobulin levels in normal human and keratoconus corneas. Invest Ophthalmol Vis Sci. 1994;35:4008-4014.

66. Robert L, Schillinger G, Moczar M, et al. Etude biochimique du keratocone. II. Arch Ophthalmol. 1970;30:590-608. 
67. Jakus MA. Ocular Fine Structure. Selected Electron Micrographs London: JA Churchill Ltd.; 1964.

68. Teng CC. Electron microscopic study of the pathology of keratoconus: Part I. Am J Ophthalmol. 1963;55:18-47.

69. Gottinger W, Aubock L. Electron microscopic findings in keratoconus. Klin Monatsbl Augenbeilkd. 1970;157:762-772.

70. Pouliquen Y, Faure JP, Limon S, et al. Extracellular deposits of corneal stroma in keratoconus: electron microscopic study [in French]. Arch Ophtalmol Rev Gen Ophtalmol. 1968;28:283-294.

71. Pouliquen Y, Graft B, DeKozak J, et al. Etude morphologique et biochimique du keratocone. I. Etude morphologique. Arch Ophthalmology. 1970;30:497-532.

72. Pouliquen Y, Graf B, Frouin MA, et al. Histological and ultrastructural interpretation of corneal lesions in keratoconus. Ber Zusammenkunft Dtsch Ophthalmol Ges. 1972;71:52-57.

73. Critchfield JW, Calandra AJ, Nesburn AB, et al. Keratoconus: I Biochemical studies. Exp Eye Res. 1988;46:953-963.

74. Buddecke E, Wollensak J. Acid mucopolysaccharide and glycoprotein in the human cornea in relation to age and keratoconus. Albrecht von Graefes Arch Klin Exp Ophthalmol. 1966;171:105-120.
75. Oxlund H, Simonsen AH. Biochemical studies of normal and keratoconus corneas. Acta Ophthalmol. 1985;63:666-669.

76. Funderburgh JL, Hevelone ND, Roth MR, et al. Decorin and biglycan of normal and pathologic human corneas. Invest Ophthalmol Vis Sci. 1998;39:1957-1964.

77. Wentz-Hunter K, Cheng EL, Ueda J, et al. Keratocan expression is increased in the stroma of keratoconus corneas. Mol Med. 2001; $7: 470-477$

78. Funderburgh JL, Panjwani N, Conrad GW, et al. Altered keratan sulfate epitopes in keratoconus. Invest Ophthalmol Vis Sci. 1989; 30:2278-2281

79. Funderburgh JL, Funderburgh ML, Rodrigues MM, et al. Altered keratan sulphate proteoglycan antigenicity in selected corneal disease. Invest Ophthalmol Vis Sci. 1990;31:419-428.

80. Wollensak J, Buddecke E. Biochemical studies on human corneal proteoglycans: a comparison of normal and keratoconic eyes. Graefes Arch Clin Exp Ophthalmol. 1990;228:517-523.

81. Wollensak G, Spoerl E, Seiler T. Riboflavin/ultraviolet-A-induced collagen crosslinking for the treatment of keratoconus. Am J Ophthalmol. 2003;135:620-627. 